\title{
The Meaning Making Mechanism of Global News Live Broadcasts from the Multimodal Perspective
}

\author{
Yang Yuhong \\ Sichuan University/Southwestern University of Finance and Economics \\ Yangyuhong_mail@126.com
}

\begin{abstract}
This paper introduces Kress's and Van Leeuwen's (2001) multimodal social-semiotic theory of communication to the field of television communication and applies this theory to examination of multimodal data generated from authentic television events. Using live broadcasts of MH370 press conferences as the example, this paper adopts the analytical framework of stratal configuration, which looks at meaning making in any communicative practice from discourse, design, production and distribution domains, and also takes into account the embedded structure of television communication featuring the data. Detailed discourse analysis is carried out to illustrate how meaning is made multimodally in the interpreter-mediated live broadcasts of global news.
\end{abstract}

Keywords-Multimodality; Multimodal social-semiotic theory of communication; Television communication; Global news

\section{INTRODUCTION}

Information globalisation has given rise to "the neoBabelianism of our age", which features "the desire for mutual, instantaneous intelligibility between human beings speaking, writing and reading different languages" (Cronin, 2003: 59). The media are becoming increasingly global as well, with the same television programmes and the same news footage being shown everywhere (Machin \& Van Leeuwen, 2007). In addition to that, instantaneity also means live communication, and in fact "live coverage of international events and multilingual productions, such as documentaries, news reports and interviews, have become central to the practice of contemporary journalism and mass media broadcasting" (Castillo, 2015: 281).

With the essential role of live communication of global news in our day-to-day lives acknowledged, we naturally see an abundance of academic studies targeting this issue, but, unfortunately, these inputs have more or less adopted a "linguistic" perspective. This preference for a linguistic perspective towards news communication probably has something to do with the view of a "monomodally conceived world" in which "“[1] anguage' was all that there was; and 'language' was regarded as a means fully capable of dealing with all human (rational) meaning" (Kress, 2010: 27). However, there is a growing perception that analyzing language alone does not suffice to understand communication. More importantly, what emits from the television is essentially "multisensory" (Vaggio, 1997), "multisemiotic" (Gambier, 2006), or "multimodal" (Kress \& Van Leeuwen, 2001), thus a panoramic description is needed to give justice to this reality.
Based on the premise that meaning making resources involved in television communication are plural, this article pursues the question of "How is meaning made multimodally in the context of television broadcast", and this question may imply smaller questions such as what is a mode? How many is this "multi" when the term "multimodal" is foregrounded? And how do they work together in achieving a unified meaning?

\section{A MULTIMODAL SOCIAL-SEMIOTIC THEORY OF COMMUNICATION}

Apparently, the term "multimodality" can work reasonably well without much detailed explanations, but a multimodal theory means much more than an assembly of different modes (not to mention the correct understanding of what a mode is). Although scholars from text linguistics and semiotics have, more or less, given their attention to multimodal aspects, it was Kress and van Leeuwen (2001), as concluded by Kaindl (2013: 257-258), "who initially sparked the development of a theory of multimodal communication". This article draws primarily upon their seminal work which established the multimodal social-semiotic theory of communication. The name of the theory suggests "the twin focus of the socialsemiotic theory and of multimodality" (Kress, 2010: 15) as well as its orientation towards communication.

Based on the idea of meaning making supported by social semiotics that meaning "arises in social environments and in social interactions" (Kress, 2010: 54), it follows to pursue the semiotic and material resources involved in the process of meaning making. Although language has long been considered as "a full means" (ibid.: 15) of meaning making along the line of conceiving the world monomodally, this conception should be overwritten as daily instances, such as face-to-face talk, classroom sessions, magazines, films, sculptures, etc., constantly remind us we are engaging with a world that consists of semiotic complexes which are bigger and fuller than language alone. Thus, in a multimodally conceived world "meaning is made in many different ways, always, in the many different modes and media which are co-present in a communicational ensemble" (Kress \& van Leeuwen, 2001: 111) and, in addition, "semiotic modes other than language are treated as fully capable of serving for representation and for communication" (ibid.: 46, emphasis original),and, most importantly, by mode they mean "semiotic resources which allow the simultaneous realisation of discourses and types of (inter)action" (ibid.: 21). In a later work, Kress (2010) expands on this notion with a list of illustrative examples: 
"Mode is a socially shaped and culturally given semiotic resource for making meaning. Image, writing, layout, music, gesture, speech, moving image, soundtrack and 3D objects are examples of modes used in representation and communication" (ibid.: 79, emphasis original).

\section{TELEVISION COMMUNICATION}

With the above elaborations on the theoretical framework that will guide the upcoming data analysis, we need to add to it one more layer, which means we need to put it in the context of television communication. Three characteristics of television-based mass communication will be pointed out here. First is the "typically asymmetrical and one-way character of television communication" (Mack, 2002: 205). Although this linearity of television is gradually challenged by the video-ondemand technology (so we choose what and when to watch instead of watching prescheduled programmes) and audience participation in TV programmes through the use of text messages, online platforms such as forums, Weibo and Wechat, the live broadcast of media event is still essentially a one-way communication, with off-screen participants only have the "power of (remote) control" (ibid.). And on the left side of the arrow, "the industrial character of message production for mass communication, involving enormous personal and technical resources and economic interest, which makes it difficult to identify and clearly distinguish between animator, author and principal of a message" (ibid.). Second, the heterogeneity of the audience. What are relevant here include people's education level (directly related to their English proficiency) and their background knowledge on the specific topic of a televised event.

Third, the concept of "embedding". As championed by Bell (1991: 53), this concept is "extraordinarily important for understanding the language of news discourse". News broadcasting means telling news stories to a mass audience, so the structure of news programmes should resemble that of ordinary storytelling. As Goffman (1981) puts it, storytelling "requires the teller to embed in his own utterances the utterances and actions of the story's characters" (ibid.: 152), and this "embedding capacity is part of something general: our linguistic ability to speak of events at any remove in time and space from the situated present" (ibid.: 3). Multiple embedding or layering is also possible in the unfolding of actual talk. In addition, this kind of layering not only embeds utterances, but also brings with them the immediate participant frameworks.

\section{DATA ANALYSIS}

Since we now have a conceptual framework featuring multimodal stratal analysis to be applied to an intrinsically embedded structure, it's time to spell out the authentic data for the following empirical efforts. Examples used in this article are taken from my video-recorded corpus of live broadcasts of 10 press conferences held by the Malaysian government after the Malaysia Airlines' Flight MH370 went off the radar on March 8th, 2014. These press conferences are covered live by a majority of international news channels and also by a number of Chinese television channels mediated by simultaneous interpreting. Live coverage by CCTV 13, the
Chinese news channel of China Central Television is chosen for analysis.

\section{A. The embedded event}

The embedded event is the press conference itself, occurring independently of its broadcast, and here "independently" means this press conference would run its course on the site no matter how and whether it is to be broadcast, although greater publicity through television transmission is one of its purposes.

After going through the data, it is safe to say that the MH370 press conferences materialise at least three overarching discourses: "aviation accident", "investigation", and "crisis management". The multimodal theory describes discourses used in representing social practices as "versions of those practices plus the ideas and attitudes that attach to them in the contexts in which we use them" (van Leeuwen, 2005: 104). In this way of description, the "aviation accident" discourse often includes (1) what happens such as the when and where of the accident, fatalities and survivors (if any), the search and rescue efforts, the number and nationalities of people on board, the cause for the accident, the operating airlines, the involvement of terrorism, etc. and (2) evaluations, for example, the common perception of air crash as catastrophic, fatal, saddening, rare, unfortunate, etc. The second discourse "investigation" is implied in the search for cause element of "aviation accident". "Investigation" involves efforts towards unsolved mysteries, questions to be answered, leads uncovered and followed, evidences presented, and report released. It is generally acknowledged that investigation should be initiated by an authoritative body and carried out by professionals. It should be thorough, unbiased, and transparent. Investigation is always done on something of negative impact. It is often difficult and it takes time. The third discourse, "risk management", is in play because, with a tragedy (potentially man-made) of such a scale occurred, it is the images of the government and the airlines that are at stake. It is a time to test the government's abilities to cope with emergencies, to search and rescue survivors, and to handle public relations. It is not only about what you do and how you do it in dealing with this accident in practical measures, but more importantly how you spread the information to the public of your position and actions concerning the emergency. In this context, this discourse includes a great deal of emphasis on the speed of response, the transparency and adequacy of information, and the position and attitude of the authorities. In addition, to protect one's image in the time of a crisis sometimes also means to publicize mainly favourable information. Thus also implied in this discourse of "risk management" is that of gatekeeping and gatekeepers. As Wadensjö (1998:67) put it, "most meetings between lay people and administrators in charge of public goods, services and control functions" are gatekeeping encounters, where intermediaries, such as the spokesman in my case, will "control the flow of information by introducing, reinforcing and excluding topics according to the rationalities of the institution". 
As the theory suggests, the best way to discuss modes used in design is through the examination of modes in their materialities in production. A number of examples are observed from the data demonstrating the modes as realised in the final semiotic ensemble. Standing positions, dress, object used, gaze, and other kinesics such as facial expression, gesture and body movement are all multimodal semiotic resources used in the construction of meaning in the embedded news event.

\section{B. Television broadcast of the events}

When the press conference kicks off, there are many ways to distribute it to a wider audience. For example, text plus photo updates on news portals, micro blog posts and comments, news report on radio, news programme with recorded footage, etc. As an international event, these distributions cannot reach the local audience without the mediation of translation. My data features live coverage assisted by simultaneous interpreters, and this distribution is a communicative event in its own right and thus allows further stratification.

\section{1) Discourse}

Apart from the discourses shaping the embedded press conference, live television carries with it its own discourses. A number of representative discourses are surveyed here: (1) television as a domestic medium (Marshall \& Werndly, 2002). Most households own a TV set and allocate to it the central place in the living room. This means a contrast of the varying locations where information is generated and the by and large fixed locality where information is received. (2) Television as storyteller (ibid.). As a mass communication medium, television communicates and informs, in a similar capacity of "storytellers of older tribal societies". It "mediates the wider culture for the community" in that in a way that it "acts to interpret the wider world, to bind society together in a consensus about what is real and what is important, and to reproduce some kind of social consensus about events and ideas"(ibid.: 9). (3) Live television as brought about by technological advancement. Michael Cronin (2003) points out the "space-time compression" in the age of globalisation. Live television plays a part in materialising this trend, as empowered by technological development. Media technology enables a virtual co-presence in place of the audience and the audio-visually recorded event, and the real-time transmission and information technology contribute to instantaneous information transmission and reception, thus a temporal copresence. With spatial and temporal gaps removed, the value of mass communication is increasingly bundled with its immediacy in the globalised world. In addition, technology also enables the viewing experience of "a range of different now-moments" (Marriot, 2007: 75) simultaneously (e.g. allowed by the affordance of different channels). However, the heavy reliance on technology also implies the possibility of technical errors, such as loss of signal. (4) Live broadcast as frontline reporting of something "big". Television goes live for things important enough to take over the regular schedules, including important, high-profile events scheduled to be covered live, and breaking news story or catastrophe that erupts unpremediatedly.

\section{2) Production}

Broadcast production is materialised through the visual and auditory channels. In the visual channel, apart from the live visual signal transmitted from Malaysia, available resources as modes including text (writing), moving image, graphics, colour, and layout are used by the broadcaster to create a complex semiotic ensemble.

For example, Kress (2010) accords to layout the status of mode, because although layout "does not name or depict" as speeches or images do, it does "dispose information in semiotic space", position "semiotic elements and their relations", "organize and indicate aspects of the social/ontological 'status' of representations" (ibid.: 92). The basic screen layout of the live broadcast features the (moving) image undoubtedly taking up the central and most place of the screen, which represents a source of information that is the most important, most engaging, and best supported by evidence. The upper corners on each side are allocated for the channel logo and the "live" legend. The lower third of the screen is packed with all sorts of textual and graphic information, which accommodates where this news is taking place, the name of the programme, a digital clock, main news topic, highlights of the current speech, and a news ticker scrolling leftwards providing real-time news updates. When another incoming footage is used to contextualise the main topic, the size of the live signal shrinks to allow the placement of the additional footage on its left.

Another example is the mode of speech. Now we take a closer look at the auditory composition of the broadcast production. It is worth noting that the interpreter only participates here and in the auditory channel, in a way that reinforces the impression of an "invisible mediator". Generally speaking, the audience hear four sources of sound/voice in this television event: the voice of the speakers at the press conference, the background sound at the press conference, the television anchor's voice, and the interpreter's voice. The broadcaster does not completely mute the soundtrack of the live signal to give place to the Chinese interpretation, but keep it at a reduced volume, to maintain the liveness as well as authenticity of the embedded event. Nevertheless, the interpreter has tremendous space, or void to fill, in the auditory dimension, and they have it all to themselves, which could imply a potentially powerful figure in this communicative practice.

In addition, the interpreter's oral production is also located in the interwoven stratal relations of his or her own communicative practice. In terms of discourse, the interpreter's performance or production is shaped by a combination of discourses including the code of ethics for interpreters and practical guidelines and professional training they have received, and discourses governing the embedded event as well as television broadcast. The interaction of these discourses influence the interpreter's output in a way that deviates from traditionally conceptualised professional standards.

Interpreters are trained to speak "in first person on behalf of the speaker" (AIIC, 1999) and expected to "just translate and translate everything" (cf. Wadensjö, 1998). However, in 
some cases, the interpreter is not representing any speaker simultaneously. Sometimes, the interpreter addresses the anchor as an active participant, uses reported speech for this whole output, and does more than translation, if part of it can be regarded as translation. These behaviours are moving away from the interpreter's role governed by professional ethics. However, the interpreter takes on a quasi-reporter role embodied in his output for good reasons. As dictated by the discourses of live television broadcast, he tries to be as informative as he can in the auditory dimension where he dominates, and makes best of the time that is available to him to set up the scene and summarise what the audience have missed so far, in a capacity that is as competent and authoritative/authorised as a frontline reporter. This is one of many examples where the interpreter's output is evidently materialising a group of discourses.

\section{CONCLUSION}

With the MH370 case used as object of study in this article, a top-down discussion was carried out to illustrate how meaning is made multimodally in the television context, with issues explored including what each stratum involves in this specific context; how each stratum interacts with the relevant others; at what place a mode is materialised for the making of a certain meaning; and where is the interpreter located in this multimodal complex.

Data analysis shows that Kress and van Leeuwen's multimodal social-semiotic theory is perfectly applicable to the examination of television communication, which helps us gain a subtler and fine-grained picture of the underlying meaning-making mechanism and the plurality of semiotic resources. Such multimodal analysis, supported by authentic multimodal transcriptions, should inspire more explorations of this kind into different genres of television communication, and generate more insights into this essentially multimodal communicative practice for scholars from communication studies, culture studies, translation studies, etc. as well as professionals from the TV industry.

\section{REFERENCES}

[1] AIIC (1999). "Practical guide for professional conference interpreters". Retrieved July 24, 2017, from https://aiic.net/page/628/practical-guidefor-professional -conference-interpreter/lang/1.

[2] Bell, A. (1991). The Language of News Media, Oxford: Blackwell.

[3] Castillo, P. (2015). "Interpreting for the mass media", in H. Mikkelson \& R. Jourdenais (eds.) The Routledge Handbook of Interpreting, London/New York: Routledge, pp. 280-301.

[4] Cronin, M. (2003). Translation and Globalization, London/New York: Routledge.

[5] Gambier, Y. (2006). "Multimodality and Audiovisual Translation", in MuTra 2006 - Audiovisual Translation Scenarios: Conference Proceedings. Retrieved July 24, 2017, from http://euroconferences. info/proceedings/2006_Proceedings/2006_Gambier_Yves.pdf

[6] Goffman, E. (1981). Forms of Talk. Philadelphia: University of Pennsylvania Press.

[7] Kaindl, K. (2013). "Multimodality and translation", in C. Millan \& F. Bartrina (eds.) The Routledge Handbook of Translation Studies, London/New York: Routledge, pp. 257-269.

[8] Kress, G. (2010). Multimodality: A Social Semiotic Approach to Contemporary Communication, London/New York: Routledge.

[9] Kress, G. \& van Leeuwen, T. (1996/2006). Reading Images - The Grammar of Visual Design, London/New York: Routledge.

[10] Kress, G. \& van Leeuwen, T. (2001). Multimodal Discourse: The Modes and Media of Contemporary Communication, London: Hodder Arnold.

[11] Machin, D. \& Van Leeuwen, T. (2007). Global Media Discourse: A Critical Introduction, London/New York: Routledge.

[12] Mack, G. (2002). "New perspectives and challenges for interpretation the example of television", in G. Garzone \& M. Viezzi (eds.) Interpreting in the 21st Century. Challenges and Opportunities, Amsterdam/Philadelphia: John Benjamins, pp. 203-213.

[13] Marriott, S. (2007). Live Television: Time, Space and the Broadcast Event, London: SAGE Publications.

[14] Marshall, J. \& Werndly, A. (2002). The Language of Television, London/ New York: Routledge.

[15] van Leeuwen, T. (2005). Introducing Social Semiotics, London/New York: Routledge.

[16] Vaggio, S. (1997). "Kinesics and the simultaneous interpreter: The advantages of listening with one's eyes and speaking with one's body", in F. Poyatos (ed.) Nonverbal Communication and Translation: New Perspectives and Challenges in Literature, Interpretation, and the Media, Amsterdam/ Philadelphia: John Benjamins, pp. 283-294.

[17] Wadensjö, C. (1998). Interpreting as Interaction. New York: Addison Wesley Longman. 